\title{
Effect of red yeast rice combined with antioxidants on lipid pattern, hs-CRP level, and endothelial function in moderately hypercholesterolemic subjects
}

\author{
This article was published in the following Dove Press journal: \\ Therapeutics and Clinical Risk Management \\ 23 February 2016 \\ Number of times this article has been viewed
}

\section{Arrigo F G Cicero \\ Martino Morbini \\ Angelo Parini \\ Riccardo Urso \\ Martina Rosticci \\ Elisa Grandi \\ Claudio Borghi}

Medical and Surgical Sciences Department, University of Bologna, Bologna, Italy
Correspondence: Arrigo F G Cicero Medical and Surgical Sciences

Department, University of Bologna, Via

Albertoni 15, 40138 Bologna, Italy

Tel +3905 I 2142224

$\mathrm{Fax}+39051390646$

Email arrigo.cicero@unibo.it

\begin{abstract}
Our aim was to test, through a crossover, double-blind, placebo-controlled randomized clinical trial, if a short-term treatment with $10 \mathrm{mg}$ monacolins combined with antioxidants could improve lipid pattern, high-sensitivity C-reactive protein (hs-CRP), and endothelial function in a small cohort of moderately hypercholesterolemic subjects. Thus, 25 healthy, moderately hypercholesterolemic subjects were consecutively enrolled and, after 4 weeks of stabilization diet, were randomized to the sequence placebo followed by a washout, monacolins or monacolins followed by a washout, placebo, with each period being 4 weeks long. At each study step, a complete lipid pattern, safety parameters, hs-CRP, and endothelial function have been measured. When compared to the placebo phase, during monacolin treatment, patients experienced a more favorable percentage change in total cholesterol (TC) (TC after monacolin treatment, $-18.35 \%$; TC after placebo treatment, $-5.39 \%$ ), low-density lipoprotein cholesterol (LDL-C) (LDL after monacolin treatment, $-22.36 \%$; LDL after placebo treatment, $-1.38 \%$ ), non-high-density lipoprotein cholesterol (HDL-C) (non-HDL after monacolin treatment, $-22.83 \%$; non-HDL after placebo treatment: $-7.15 \%$ ), hs-CRP (hs-CRP after monacolin treatment: $-2.33 \%$; hs-CRP after placebo treatment, $2.11 \%$ ), and endothelial function (pulse volume displacement after monacolin treatment, $18.59 \%$; pulse volume displacement after placebo treatment, $-6.69 \%$ ). No significant difference was observed with regard to triglycerides, HDL-cholesterol, and safety parameters. On the basis of our data, we could demonstrate that a $10 \mathrm{mg}$ monacolin nutraceutical treatment appears to safely reduce cholesterolemia, hs-CRP, and markers of vascular remodeling in moderately hypercholesterolemic subjects. These results need to be confirmed in larger patient samples and in studies with longer duration.
\end{abstract}

Keywords: monacolins, LDL-cholesterol, metalloproteinases, high-sensitivity C-reactive protein, nutraceutical, clinical trial

\section{Introduction}

A relatively large number of dietary supplements and nutraceuticals have been studied for their supposed or demonstrated ability to reduce cholesterolemia in humans., ${ }^{1,2}$ These supplements include soluble fibers, phytosterols, soy proteins, $\omega-3$ polyunsaturated fatty acids, ${ }^{3,4}$ monacolins, policosanols, berberine, ${ }^{5}$ and garlic extracts. In particular, Chinese red yeast rice is a dietary supplement made by fermenting the yeast, Monascus purpureus, over rice. Monascus yeast produces a family of substances called monacolins, including monacolin K. Monacolins act as reversible inhibitors of the 3-hydroxy-3-methyl-glutaryl-coenzyme A (HMG-CoA) reductase, a key enzyme 
in cholesterol biosynthesis. In addition to the inhibition of $\mathrm{HMG}-\mathrm{CoA}$ reductase, red yeast rice has been found to contain sterols ( $\beta$-sitosterol, campesterol, stigmasterol, and sapogenin), isoflavones and isoflavone glycosides, and monounsaturated fatty acids, ${ }^{6,7}$ all capable of lowering lowdensity lipoprotein cholesterol (LDL-C). ${ }^{8}$ Unpurified red yeast rice could, however, contain other active components with potentially negative effects, such as dehydromonacolins or decalin derivatives. ${ }^{9,10}$ Several trials conducted in the People's Republic of China showed that consumption of red yeast rice reduced cholesterol concentrations by $11 \%-32 \%$ and triacylglycerol concentrations by $12 \%-19 \%$, both in animal and human models. ${ }^{11,12}$ These positive effects were also confirmed in an American population after 12 weeks of treatment ${ }^{13}$ and in a Norwegian population after 16 weeks of treatment, in two randomized, double-blind, placebocontrolled trials. ${ }^{14}$ Moreover, Guardamagna et al ${ }^{15}$ were the first to demonstrate the effectiveness of monacolins even in children aged 8-16 years, affected with both heterozygous familial hypercholesterolemia and familial combined hyperlipidemia. In addition to being effective in improving lipid profile, red yeast rice also proved to be well tolerated for 24 weeks, without a recurrence of myalgia in patients with a history of statin-associated myalgia. ${ }^{16}$ Similarly, Halbert et $\mathrm{al}^{17}$ reported that red yeast rice was as well tolerated as pravastatin and achieved a comparable reduction of LDL-C in a population previously intolerant to statins.

Considering the positive results reported in literature, the European Agency on Food Safety recognized that there is a cause and effect relationship between the consumption of monacolin $\mathrm{K}$ contained in red yeast rice and maintenance of normal blood LDL-C concentration. ${ }^{18}$ In a previous study performed by our group, we confirmed this effect in Italian subjects following a Mediterranean diet. ${ }^{19}$

Our current aim is to evaluate if this effect translates to an improvement of endothelial function, with a further crossover, double-blind, randomized, short-term clinical trial.

\section{Materials and methods Study design}

This double-blind, placebo-controlled, randomized clinical trial (Registration number: NCT02492464) was carried out on 25 moderately hypercholesterolemic, nonsmoking, pharmacologically untreated subjects, who as primary prevention for cardiovascular diseases, consecutively enrolled in the ambulatory service of cardiovascular disease prevention in the Medical and Surgical Sciences Department of the University of Bologna.
Inclusion criteria were as follows: age between 18 and 70 years and LDL-C level between 130 and $190 \mathrm{mg} / \mathrm{dL}$, confirmed in at least two sequential checks before signing the consent form.

Exclusion criteria were as follows: personal history of cardiovascular disease or risk equivalents; triglycerides (TG) $>400 \mathrm{mg} / \mathrm{dL}$ and/or high-density lipoprotein cholesterol (HDL-C) $<35 \mathrm{mg} / \mathrm{dL}$; obesity (body mass index $>30 \mathrm{~kg} / \mathrm{m}^{2}$ ); use of lipid-lowering drugs or drugs affecting lipid metabolism; and known thyroid, liver, renal, or muscle diseases.

The study was fully conducted in accordance with the Declaration of Helsinki, study protocol was approved by the Ethical Committee of the University of Bologna, and written informed consent was obtained from all patients before their inclusion in the study.

At baseline, patients were given standard behavioral and qualitative dietary suggestions to correct unhealthy habits. Standard diet advice was given by a dietitian and/or a specialist doctor, who periodically provided instruction on dietary intake recording procedures as part of a behavior modification program, and then later used the subject's food diaries for counseling. In particular, subjects were instructed to follow general indications of a Mediterranean diet, avoiding excessive intake of dairy and red meat derived products, and maintaining overall constant dietary habits. Individuals were also generically encouraged to increase their physical activity by walking briskly for 20-30 minutes, three to five times per week, or by cycling for the same amount of time.

\section{Treatment}

After 4 weeks of diet and physical activity, patients were allocated to treatment either with an indistinguishable pill of placebo or with an active product containing $10 \mathrm{mg}$ monacolins from $M$. purpureus and a mix of antioxidants (green tea dry extract, $100 \mathrm{mg}$; coenzyme Q10, $20 \mathrm{mg}$; astaxanthin, $2 \mathrm{mg}$; resveratrol, $20 \mathrm{mg}$; and quercetin, $50 \mathrm{mg}$ ), kindly offered by Laborest S.p.A. (Nerviano, Milan, Italy). The red yeast rice extract used was certified to be highly purified in monacolins, without chromatographically detectable levels of dehydromonacolins, decalin derivatives, and contaminants.

After 4 weeks of treatment, patients were asked to observe a 4-week washout period, and they were then assigned to the alternative treatment for a further period of 4 weeks. Clinical and laboratory data were obtained at baseline, at the end of the first treatment period, after the washout, and again after the second treatment period. Randomization was obtained using a drawing of envelopes containing randomization codes prepared by an independent statistician and 
by using specific software. The envelopes were then further mixed and distributed to the investigators who assigned the randomization code in a progressive way to the enrolled subjects. A copy of the code was provided only to the person responsible for performing the statistical analysis.

Throughout the study, we instructed patients to take the first dose of the new product on the day after they received it in a blinded box. At the same time, all unused products were retrieved for inventory. Product compliance was assessed by counting the number of product doses returned at the time of specified clinic visits.

\section{Assessments}

All plasma parameters were obtained after a 12-hour overnight fast. Venous blood samples were drawn by a nurse from all patients between 8 am and $9 \mathrm{am}$. The plasma used was obtained by addition of $\mathrm{Na}_{2}$ EDTA $(1 \mathrm{mg} / \mathrm{mL})$ and centrifuged at $3,000 \times g$ for 15 minutes at $48^{\circ} \mathrm{C}$. Immediately after centrifugation, plasma samples were frozen and stored at $-80^{\circ} \mathrm{C}$ for no more than 3 months. The following parameters were evaluated via standardized methods: ${ }^{20}$ total cholesterol (TC), HDL-C, TG, LDL-C, apolipoprotein B, apolipoprotein AI, glucose, creatinine, liver transaminases, and creatine-phosphokinase. All measurements were centrally performed in the laboratory of our department.

High-sensitivity C-reactive protein (hs-CRP) was measured with the use of latex-enhanced immunonephelometric assays on a BN II analyzer (Dade Behring, Newark, DE, USA). The intra-assay and interassay coefficients of variation were $5.7 \%$ and $1.3 \%$, respectively. ${ }^{21}$

Endothelial function was evaluated through the Endocheck $^{\circledR}$ (BC Biomedical Laboratories Ltd, Vancouver, BC, Canada), a method embedded within the Vicorder $^{\circledR}$ device (PRN Vascular, Fall River, MA, USA), which records brachial pulse volume (PV) waveforms, at baseline and during reactive hyperemia. Reactive hyperemia was provoked through PV displacement, obtained by inflating a cuff positioned distally around the forearm. After a 10-minute rest, brachial blood pressure was evaluated, and PV waveforms were recorded at the baseline for 10 seconds. Then, the cuff was inflated to $200 \mathrm{mmHg}$ for 5 minutes, and PV waveforms were recorded for 3 minutes after cuff release. PV displacement was then calculated as a percent change in the PV waveform area, comparing waveforms during and before hyperemia through the equation $\sqrt{ } \mathrm{PV}_{2} / \mathrm{PV}_{1}$, where $\mathrm{PV}_{1}$ represents $\mathrm{PV}$ at the baseline and $\mathrm{PV}_{2}$ represents $\mathrm{PV}$ during hyperemia. ${ }^{22}$

\section{Statistical analyses}

Data have been analyzed using intention to treat by means of the Statistical Package for Social Science (SPSS) version 19.0 (IBM Corporation, Armonk, NY, USA), for Windows. The sample size suggested to detect a mean difference of $10 \%$ in endothelial reactivity between active treatment and placebo, with a power of 0.90 and an $\alpha$ error of 0.05 , was at least 12 subjects per group. Normally distributed baseline characteristics of the population have been compared using Student's $t$-test and $\chi^{2}$ test, followed by Fisher's exact test for categorical variables. Two-way analysis of variance for crossover design was used to assess the effect of treatment during the use of placebo or monacolins. All data are expressed as mean and standard deviation. To verify the basic assumptions of crossover design, besides the evaluation of period effect, the presence of a carryover effect was excluded. A $P$-value of $<0.05$ was considered significant for all tests.

\section{Results}

Enrolled patients were age and sex matched. The baseline characteristics of patients assigned to the two different types of treatment (placebo-monacolins or monacolinsplacebo) were similar, and no significant differences were observed regarding the studied parameters (Table 1). No patient dropped out from the study because of adverse events, although two patients suffered from a mild myalgia at the beginning of the red yeast rice treatment.

From the randomization visit to the end of the study, the enrolled subjects maintained a similar dietary pattern overall, without significant change in total energy, TC, and total saturated fatty acid intake.

When compared to the placebo phase, during monacolin treatment, patients experienced a more favorable percentage change in TC (TC after monacolin treatment, $-18.35 \%$; TC after placebo treatment, $-5.39 \%$ ), LDL-C (LDL after monacolin treatment, $-22.36 \%$; LDL after placebo treatment, $-1.38 \%$ ), non-HDL-C (non-HDL after monacolin treatment, $-22.83 \%$; non-HDL after placebo treatment, $-7.15 \%$ ), hs-CRP (hs-CRP after monacolin treatment, $-2.33 \%$; hs-CRP after placebo treatment, 2.11\%), and endothelial function (PV displacement after monacolin treatment, 18.59\%; PV displacement after placebo treatment, $-6.69 \%$ ).

No significant difference has been detected comparing pre- and posttreatment values with regard to TG, HDL-C, apolipoproteins, glucose, transaminases, creatinine, and creatine-phosphokinase in both treatment groups (Table 2). 
Table I Main characteristics of the investigated parameters at baseline in patients treated with the tested nutraceutical or placebo

\begin{tabular}{|c|c|c|c|c|}
\hline \multirow[t]{2}{*}{ Variable } & \multicolumn{2}{|c|}{ Placebo $(n=13 ; M, 5 ; F, 8)$} & \multicolumn{2}{|c|}{ Active treatment $(n=\mid 2 ; M, 5 ; F, 7)$} \\
\hline & Mean & SD & Mean & SD \\
\hline Age (years) & 52.78 & 8.33 & 53.65 & 8.67 \\
\hline Total energy intake $(\mathrm{kcal})$ & 2,364 & 136 & 2,385 & 156 \\
\hline Fat dietary intake (\% on total energy) & 28.9 & 3.1 & 29.4 & 3.9 \\
\hline Saturated fat intake (\% on total energy) & II.I & 1.3 & 11.4 & 0.9 \\
\hline P/S fatty acids ratio & 1.1 & 0.1 & 1.2 & 0.2 \\
\hline n-6 PUFA/n-3 PUFA & 0.9 & 0.2 & 0.8 & 0.3 \\
\hline Protein intake (\% on total energy) & 16.6 & 2.0 & 16.8 & 1.8 \\
\hline Carbohydrate intake (\% on total energy) & 54.5 & 4.2 & 53.8 & 4.4 \\
\hline Simple sugar intake (\% on total energy) & 8.2 & 1.3 & 8.4 & 1.5 \\
\hline Cholesterol intake (mg) & 204.2 & 10.2 & 202.8 & 11.6 \\
\hline Body mass index $\left(\mathrm{kg} / \mathrm{m}^{2}\right)$ & 26.7 & 0.7 & 26.8 & 0.9 \\
\hline $\mathrm{SBP}(\mathrm{mmHg})$ & 135.1 & 5.77 & 135.04 & 5.54 \\
\hline $\mathrm{DBP}(\mathrm{mmHg})$ & 85.6 & 4.02 & 83.36 & 5.58 \\
\hline Pulse pressure $(\mathrm{mmHg})$ & 49.4 & 4.77 & 51.68 & 5.24 \\
\hline Mean arterial pressure $(\mathrm{mmHg})$ & 110.4 & 4.36 & 109.20 & 4.90 \\
\hline Total cholesterol (mg/dL) & 224.6 & 24.10 & 237.04 & 32.81 \\
\hline $\mathrm{HDL}-\mathrm{C}(\mathrm{mg} / \mathrm{dL})$ & 36.5 & 6.75 & 36.88 & 8.07 \\
\hline LDL-C (mg/dL) & 152.3 & 25.40 & 167.68 & 23.81 \\
\hline Triglycerides (mg/dL) & 169.4 & 56.86 & 162.40 & 47.78 \\
\hline Non-HDL-C (mg/dL) & 188.8 & 26.59 & 200.16 & 34.57 \\
\hline Apolipoprotein $\mathrm{Al}$ (mg/dL) & 115.6 & 17.25 & 120.46 & 17.96 \\
\hline Apolipoprotein B (mg/dL) & 91.6 & 12.37 & 91.00 & 13.52 \\
\hline Fasting plasma glucose (mg/dL) & 92.8 & 7.78 & 95.32 & 9.38 \\
\hline Creatinine $(\mathrm{mg} / \mathrm{dL})$ & 21.6 & 4.95 & 21.32 & 4.99 \\
\hline Creatine-phosphokinase (U/L) & 22.8 & 8.95 & 26.24 & 11.47 \\
\hline AST (U/L) & I.I & 0.15 & 1.05 & 0.13 \\
\hline $\mathrm{ALT}(\mathrm{U} / \mathrm{L})$ & 121.6 & 37.00 & 131.60 & 36.95 \\
\hline hs-CRP (mg/L) & 1.9 & 0.35 & 2.15 & 0.43 \\
\hline Pulse volume changes (\%) & 64.3 & 12.1 & 62.4 & 11.6 \\
\hline
\end{tabular}

Notes: Descriptive values reported as mean and SD. The subjects were cross-matched for all the tested variables.

Abbreviations: M, male; F, female; SD, standard deviation; P/S, polyunsaturated/saturated; PUFA, polyunsaturated fatty acid; SBP, systolic blood pressure; DBP, diastolic blood pressure; LDL-C, low-density lipoprotein cholesterol; HDL-C, high-density lipoprotein cholesterol; AST, aspartate transaminase; ALT, alanine transaminase; hs-CRP, high sensitivity C-reactive protein.

Table 2 Changes in the investigated parameters after placebo and monacolin treatment (cumulative data comparing pre-/posttreatment phases)

\begin{tabular}{|c|c|c|c|c|c|c|}
\hline \multirow[t]{2}{*}{$\Delta\left(T_{0}-T_{1}\right)$} & \multicolumn{3}{|c|}{ Placebo $(n=25)$} & \multicolumn{3}{|c|}{ Active treatment $(n=25)$} \\
\hline & Mean & SD & $P$-value vs baseline & Mean & SD & $P$-value vs baseline \\
\hline$\Delta$ Total cholesterol (mg/dL) & -12.1 & 11.2 & $<0.001$ & $-43.5^{*}$ & 19.7 & $<0.001$ \\
\hline$\Delta \mathrm{HDL}-\mathrm{C}(\mathrm{mg} / \mathrm{dL})$ & +1.4 & 4.1 & 0.156 & +1.6 & 5.5 & 0.134 \\
\hline$\Delta \mathrm{LDL}-\mathrm{C}(\mathrm{mg} / \mathrm{dL})$ & -2.1 & 13.9 & 0.462 & $-37.5^{*}$ & 14.1 & $<0.001$ \\
\hline$\Delta$ Triglycerides $(\mathrm{mg} / \mathrm{dL})$ & -57.8 & 78.5 & 0.001 & -39.7 & 58.7 & 0.003 \\
\hline$\Delta$ Non-HDL-C (mg/dL) & -13.5 & 12.3 & $<0.001$ & $-45.7^{*}$ & 19.2 & $<0.001$ \\
\hline$\Delta$ Apolipoprotein AI (mg/dL) & +15.6 & 26.1 & 0.660 & +12.3 & 25.3 & 0.634 \\
\hline$\Delta$ Apolipoprotein B (mg/dL) & -0.2 & 11.6 & 0.958 & $-11.8^{*}$ & 12.5 & 0.038 \\
\hline$\Delta \mathrm{FPG}(\mathrm{mg} / \mathrm{dL})$ & -1.6 & 8.9 & 0.394 & -2.4 & $1 \mathrm{I} .4$ & 0.369 \\
\hline$\Delta$ Creatinine $(\mathrm{mg} / \mathrm{dL})$ & +0.07 & 0.11 & 0.287 & -0.03 & 0.14 & 0.334 \\
\hline$\Delta \mathrm{CPK}(\mathrm{U} / \mathrm{L})$ & +16.4 & 34.5 & 0.269 & +24.4 & 44.3 & 0.298 \\
\hline$\Delta \mathrm{AST}(\mathrm{U} / \mathrm{L})$ & -4.6 & II.I & 0.163 & -2.2 & 4.6 & 0.133 \\
\hline$\Delta \mathrm{ALT}(\mathrm{U} / \mathrm{L})$ & -5.4 & 14.7 & 0.160 & -1.2 & 10.2 & 0.422 \\
\hline$\Delta \mathrm{hs}-\mathrm{CRP}(\mathrm{mg} / \mathrm{L})$ & +0.04 & 0.07 & 0.410 & $-0.05 *$ & 0.05 & $<0.001$ \\
\hline$\Delta$ Pulse volume $(\%)$ & -4.3 & 10.3 & 0.070 & $+11.6^{*}$ & 9.8 & 0.022 \\
\hline
\end{tabular}

Notes: Two-way analysis of variance for crossover design was used to assess the effects of treatment during treatment with placebo or monacolins. $* P<0.01$ vs placebo. All the data are expressed as mean and SD.

Abbreviations: SD, standard deviation; HDL-C, high-density lipoprotein cholesterol; LDL-C, low-density lipoprotein cholesterol; FPG, fasting plasma glucose; CPK, creatinephosphokinase; AST, aspartate transaminase; ALT, alanine transaminase; hs-CRP, high sensitivity C-reactive protein. 


\section{Discussion}

In line with what has already been reported in the literature for other population groups, ${ }^{23}$ our study shows that the favorable effects induced by $10 \mathrm{mg}$ monacolins are also found in hypercholesterolemic Mediterranean subjects, who were observed to experience a better decrease in TC and LDL-C when compared to placebo. In fact, similar to our previous study, we recorded a reduction of $18.35 \%$ for TC and $22.36 \%$ for LDL-C, respectively, in line with the results of a recently published systematic review. ${ }^{24}$

We also analyzed the effect of monacolins on hs-CRP, an inflammatory marker shown to independently predict myocardial infarction, stroke, and peripheral artery disease. ${ }^{25}$ hs-CRP is known to play a role in enhancement of leukocyte reactivity, complement fixation, modulation of platelet activation, and clearance of cellular debris from sites of active inflammation. ${ }^{26}$ We observed a decrease of hs-CRP with monacolins, in line with the results of Liu et $\mathrm{al}^{27}$ and with another Italian study testing a combination of red yeast rice, Silybum marianum, and octacosanol. ${ }^{28}$ The explanation could be that monacolins may control chronic inflammation partly through an indirect anti-inflammatory effect, resulting from lipid-lowering and other processes that reduce triggers and stimulators, rather than a direct anti-inflammatory effect from the naturally occurring statin-like elements.

The association of endothelial dysfunction with a higher cardiovascular risk is widespread and is demonstrated in various populations, ${ }^{29,30}$ and several methods have been tested for its assessment, ${ }^{31,32}$ endothelium-dependent flowmediated vasodilation (FMD) via ultrasound being the most commonly used. ${ }^{33} \mathrm{We}$ evaluated the endothelial function of the subjects in our study through the Endocheck ${ }^{\circledR}$ device (BC Biomedical Laboratories Ltd): changes in brachial PV waveform area during hyperemia were greater in patients treated with monacolins than in patients treated with placebo (PV after monacolin treatment: 18.59\%; PV after placebo treatment: $-6.69 \%$ ). Moreover, PV waveform area was significantly and positively enhanced during hyperemia in the former group of patients, while it was slightly diminished in the latter group.

FMD has already been found to be enhanced in at least two other studies carried out after the use of a compound containing red yeast rice, berberine, and policosanols. ${ }^{34,35}$ Moreover, several studies registered increased values of FMD after treatment with different antioxidants both in healthy populations ${ }^{36,37}$ and, more specifically, in hypertensive patients. ${ }^{38}$ On the other hand, a paper by Wray et $\mathrm{al}^{39}$ reports, together with an acute improvement in endothelial function in elderly subjects, a remarkable reduction in FMD in younger subjects, that the authors suggest could be due to a free radicals effect.

In our study, monacolins were well tolerated: no variations of liver, renal, and muscle safety parameters were recorded, as expected based on previous studies. ${ }^{16,17}$

Of course, our study has some relevant limitations. First, the patient sample is quite small, even if the study strength is improved by a crossover design where patients are all treated with both placebo and active treatment, and the study was sufficiently powered to detect eventual differences in endothelial function. Another limitation is the short duration of the study, but our aim was to detect a short-term effect of the tested nutraceuticals on endothelial function. Finally, efficacy data were based on a relatively low number of laboratory and instrumental parameters.

\section{Conclusion}

On the basis of our data, a nutraceutical containing $10 \mathrm{mg}$ monacolins appears to safely reduce cholesterolemia, hsCRP, and endothelial function in moderately hypercholesterolemic subjects. These results need to be confirmed in larger patient samples and in studies with longer duration.

\section{Acknowledgment}

The study was supported by University of Bologna institutional funding.

\section{Disclosure}

The authors report no conflicts of interest in this work.

\section{References}

1. Cicero AF, Tartagni E, Ertek S. Nutraceuticals for metabolic syndrome management: from laboratory to benchside. Curr Vasc Pharmacol. 2014;12(4):565-571.

2. Cicero AF, Ferroni A, Ertek S. Tolerability and safety of commonly used dietary supplements and nutraceuticals with lipid-lowering effects Expert Opin Drug Saf. 2012;11(5):753-766.

3. Derosa G, Cicero AF, Fogari E, D’Angelo A, Bonaventura A, Maffioli P. Effects of n-3 PUFAs on insulin resistance after an oral fat load. Eur J Lipid Sci Technol. 2011;113(8):950-960.

4. Derosa G, Cicero AF, Fogari E, et al. Effects of n-3 PUFAs effects on post-prandial variation of metalloproteinases, inflammatory and insulin resistance parameters in dyslipidemic patients: evaluation with euglycemic clamp and oral fat load. J Clin Lipidol. 2012;6(6):553-564.

5. Derosa G, Maffioli P, Cicero AF. Berberine on metabolic and cardiovascular risk factors: an analysis from preclinical evidences to clinical trials. Expert Opin Biol Ther. 2012;12(8):1113-1124.

6. Heber D, Lembertas A, Lu QY, Bowerman S, Go VL. An analysis of nine proprietary Chinese red yeast rice dietary supplements: implications of variability in chemical profile and contents. J Altern Complement Med. 2001;7(2):133-139.

7. Ma J, Li Y, Ye Q, et al. Constituents of red yeast rice, a traditional Chinese food and medicine. J Agric Food Chem. 2000;48(11):5220-5225. 
8. Goldstein MR. Effects of dietary phytosterols on cholesterol metabolism and atherosclerosis. Am J Med. 2000;109(1):72-73.

9. Zhu L, Yau LF, Lu JG, et al. Cytotoxic dehydromonacolins from red yeast rice. J Agric Food Chem. 2012;60(4):934-939.

10. Zhu L, Lu JG, Li T, et al. Immunosuppressive decalin derivatives from red yeast rice. $J$ Nat Prod. 2012;75(4):567-571.

11. Hasani-Ranjbar S, Nayebi N, Moradi L, Mehri A, Larijani B, Abdollahi M. The efficacy and safety of herbal medicines used in the treatment of hyperlipidemia: a systematic review. Curr Pharm Des. 2010;16(26): 2935-2947.

12. Wang J, Su M, Lu Z, et al. Clinical trial of extract of Monascus purpureus (red yeast) in the treatment of hyperlipidemia. Chin J Exp Ther Prep Chin Med. 1995;12:1-5.

13. Heber D, Yip I, Ashley JM, Elashoff DA, Elashoff RM, Go VL. Cholesterol-lowering effects of a proprietary Chinese red-yeast-rice dietary supplement. Am J Clin Nutr. 1999;69(2):231-236.

14. Bogsrud MP, Ose L, Langslet G, et al. HypoCol (red yeast rice) lowers plasma cholesterol - a randomized placebo controlled study. Scand Cardiovasc J. 2010;44(4):197-200.

15. Guardamagna O, Abello F, Baracco V, Stasiowska B, Martino F. The treatment of hypercholesterolemic children: efficacy and safety of a combination of red yeast rice extract and policosanols. Nutr Metab Cardiovasc Dis. 2011;21(6):424-429.

16. Becker DJ, Gordon J, Halbert SC, French B, Morris PB, Rader DJ. Red yeast rice versus placebo in dyslipidemic, statin-intolerant patients enrolled in a therapeutic lifestyle program: a randomized, controlled trial. Ann Intern Med. 2009;150(12):830-839.

17. Halbert SC, French B, Gordon RY, et al. Tolerability of red yeast rice $(2,400 \mathrm{mg}$ twice daily) versus pravastatin ( $20 \mathrm{mg}$ twice daily) in patients with previous statin intolerance. Am J Cardiol. 2010;105(2): 198-204.

18. European Food Safety Authority. Scientific opinion on the substantiation of health claims related to monacolin $\mathrm{K}$ from red yeast rice and maintenance of normal blood LDL cholesterol concentrations (ID 1648, 1700) pursuant to Article 13(1) of Regulation (EC) No 1924/2006. EFSA J. 2011;9(7):2304-2319.

19. Cicero AF, Derosa G, Parini A, et al. Red yeast rice improves lipid pattern, hs-CRP and vascular remodeling parameters in moderately hypercholesterolemic Italian subjects. Nutr Res. 2013;33(8): 622-628.

20. Cicero AF, D'Addato S, Reggi A, Reggiani GM, Borghi C; on behalf of the Brisighella Heart Study. Hepatic steatosis index and lipid accumulation product as middle-term predictors of incident metabolic syndrome in a large population sample: data from the Brisighella Heart Study. Intern Emerg Med. 2013;8(3):265-267.

21. Rifai N, Tracy RP, Ridker PM. Clinical efficacy of an automated high-sensitivity c-reactive protein assay. Clin Chem. 1999;45(12): 2136-2141.

22. Day LM, Maki-Petaja KM, Wilkinson IB, McEniery CM. Assessment of brachial artery reactivity using the Endocheck: repeatability, reproducibility and preliminary comparison with ultrasound. Artery Res. 2013;7(3-4):119-120.

23. Lin CC, Li TC, Lai MM. Efficacy and safety of Monascus purpureus Went rice in subjects with hyperlipidemia. Eur J Endocrinol. 2005;153(5):679-686
24. Gerards MC, Terlou RJ, Yu H, Koks CH, Gerdes VE. Traditional Chinese lipid-lowering agent red yeast rice results in significant LDL reduction but safety is uncertain - a systematic review and metaanalysis. Atherosclerosis. 2015;240(2):415-423.

25. Ridker PM. A test in context: high-sensitivity C-reactive protein. $J \mathrm{Am}$ Coll Cardiol. 2016;67(6):712-723.

26. Zwaka TP, Hornbach V, Torzewski J. C-reactive protein mediated lipoprotein uptake by macrophages. Circulation. 2001;103(9):1194-1197.

27. Liu L, Zhao SP, Cheng YC, Li YL. Xuezhikang decreases serum lipoprotein(a) and $\mathrm{C}$-reactive protein concentrations in patients with coronary heart disease. Clin Chem. 2003;49(8):1347-1352.

28. Derosa G, Bonaventura A, Bianchi L, et al. A randomized, placebocontrolled study on the effects of a nutraceutical combination of red yeast rice, Silybum marianum and octacosanol on lipid profile, endothelial and inflammatory parameters. J Biol Regul Homeost Agents. 2014; 28(2):317-324.

29. van Sloten TT, Henry RM, Dekker JM, et al. Endothelial dysfunction plays a key role in increasing cardiovascular risk in type 2 diabetes: the Hoorn study. Hypertension. 2014;64(6):1299-1305.

30. Hirata Y, Sugiyama S, Yamamoto E, et al. Endothelial function and cardiovascular events in chronic kidney disease. Int J Cardiol. 2014;173(3): 481-486.

31. Deanfield J, Donald A, Ferri C, et al; Working Group on Endothelin and Endothelial Factors of the European Society of Hypertension. Endothelial function and dysfunction. Part I: methodological issues for assessment in the different vascular beds: a statement by the Working Group on Endothelin and Endothelial Factors of the European Society of Hypertension. J Hypertens. 2005;23(1):7-17.

32. Felmeden DC, Lip GY. Endothelial function and its assessment. Expert Opin Investig Drugs. 2005;14(11):1319-1336.

33. Corretti MC, Anderson TJ, Benjamin EJ, et al. Guidelines for the ultrasound assessment of endothelial-dependent flow-mediated vasodilation of the brachial artery. J Am Coll Cardiol. 2002;39(2):257-265.

34. Affuso F, Ruvolo A, Micillo F, Saccà L, Fazio S. Effects of a nutraceutical combination (berberine, red yeast rice and policosanols) on lipid levels and endothelial function randomized, double-blind, placebocontrolled study. Nutr Metab Cardiovasc Dis. 2010;20(9):656-661.

35. Affuso F, Mercurio V, Ruvolo A, et al. A nutraceutical combination improves insulin sensitivity in patients with metabolic syndrome. World J Cardiol. 2012;4(3):77-83.

36. Khan F, Ray S, Craigie AM, et al. Lowering of oxidative stress improves endothelial function in healthy subjects with habitually low intake of fruit and vegetables: a randomized controlled trial of antioxidant- and polyphenol-rich blackcurrant juice. Free Radic Biol Med. 2014;72:232-237.

37. Siasos G, Tousoulis D, Kokkou E, et al. Favorable effects of concord grape juice on endothelial function and arterial stiffness in healthy smokers. Am J Hypertens. 2014;27(1):38-45.

38. Plantinga Y, Ghiadoni L, Magagna A, et al. Supplementation with vitamins $\mathrm{C}$ and $\mathrm{E}$ improves arterial stiffness and endothelial function in essential hypertensive patients. Am J Hypertens. 2007;20(4):392-397.

39. Wray DW, Nishiyama SK, Harris RA, et al. Acute reversal of endothelial dysfunction in the elderly after antioxidant consumption. Hypertension . 2012;59(4):818-824.
Therapeutics and Clinical Risk Management

\section{Publish your work in this journal}

Therapeutics and Clinical Risk Management is an international, peerreviewed journal of clinical therapeutics and risk management, focusing on concise rapid reporting of clinical studies in all therapeutic areas, outcomes, safety, and programs for the effective, safe, and sustained use of medicines. This journal is indexed on PubMed Central, CAS,

\section{Dovepress}

EMBase, Scopus and the Elsevier Bibliographic databases. The manuscript management system is completely online and includes a very quick and fair peer-review system, which is all easy to use. Visit http://www.dovepress.com/testimonials.php to read real quotes from published authors. 